Original Research Paper

\title{
Gears-Part I
}

\author{
${ }^{1}$ Relly Victoria V. Petrescu, ${ }^{2}$ Raffaella Aversa, \\ ${ }^{3}$ Bilal Akash, ${ }^{4}$ Ronald B. Bucinell, ${ }^{5}$ Juan M. Corchado, \\ ${ }^{2}$ Antonio Apicella and ${ }^{1}$ Florian Ion T. Petrescu

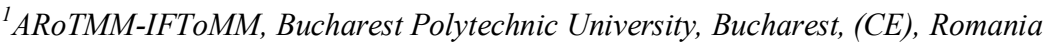 \\ ${ }^{2}$ Advanced Material Lab, Department of Architecture and Industrial Design, \\ Second University of Naples, 81031 Aversa (CE), Italy \\ ${ }^{3}$ Dean of School of Graduate Studies and Research, American University of Ras Al Khaimah, UAE \\ ${ }^{4}$ Union College, USA \\ ${ }^{5}$ University of Salamanca, Spain
}

Article history

Received: 29-12-2016

Revised: 03-01-2017

Accepted: 09-05-2017

Corresponding Author:

Florian Ion T. Petrescu

ARoTMM-IFToMM,

Bucharest Polytechnic

University, Bucharest, (CE),

Romania

Email: scipub02@gmail.com
Abstract: The gears are today the most widespread and most frequently used mechanical transmissions, all over the world. They must be the factory on an industrial scale, everywhere and have a variety of uses, being extremely important for both the heavy machines of industrial buildings, as well as for domestic appliances, electronics, etc. meet the excessive size normal, big or even huge (used from ships, heavy machines or in energy), but also for the tools watches, or for devices of sizes micro. The work of front wishes to make an overview of the tools and then an introduction to the study of their general and a study customized for gears with fixed. The methods listed for the gears with fixed, can then be customized and used and the gears Planetary Drive (with axis elements). The work of the front and the original components, very much, such as: Geometry, forces, velocities, powers, outputs (gears), which form part of the actual dynamics of the mechanisms and also the most important criterion in respect of the performance of a mechanism.

Keywords: Kinematics, Forces, Velocities, Powers, Gears, Efficiency, Geometry, Synthesis, Yield

\section{Introduction}

A gear is a mechanical system consisting of two meshing gears serving: Or to the transmission of the rotational movement between them; Or to the propulsion of a fluid (called a gear pump).

In the case of the transmission of motion, the two toothed wheels are in contact with each other and transmit power by obstacle. A gear is composed of a pinion, which is called the only wheel or the smallest wheel and a wheel, a rack, a crown or a screw. When more than two gear wheels are present, this is called a gear train (Fig. 1). The most widespread profile, in general mechanics, is the involute profile of a circle most often used in general mechanics; the epicycloid profile was used most often in watch mechanisms. Different types of teeth can be distinguished: Straight tooth; Helical teeth; Chevron teeth; The collared gears.
Similarly, there are several types of gears: Parallel axis gears; with concurrent axes; with non-concurrent axes including worm gear and worm gear - and rack and pinion gears.

The oldest known gear mechanism is the Antikythera machine.

In watchmaking, do not confuse with mobile, assembly of a wheel mounted on its pinion.

The gear is one of eight simple machines. Gears are used in all branches of mechanics to transmit movements, from watchmaking to reducers of heavy industry. The transmission is very energy efficient since it is generally more than $95 \%$ under correct conditions of assembly and lubrication during operation.

The ratio of angular velocities obtained between the input and the output, also known as the "gear ratio" and the "transmission ratio", depends only on the number of teeth of the wheels in contact. 


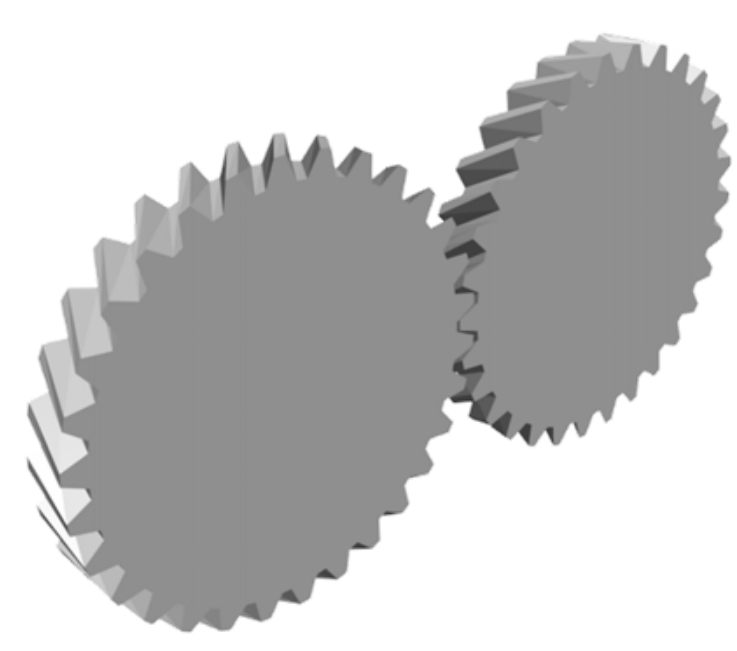

Fig. 1. An external contact, helical gear

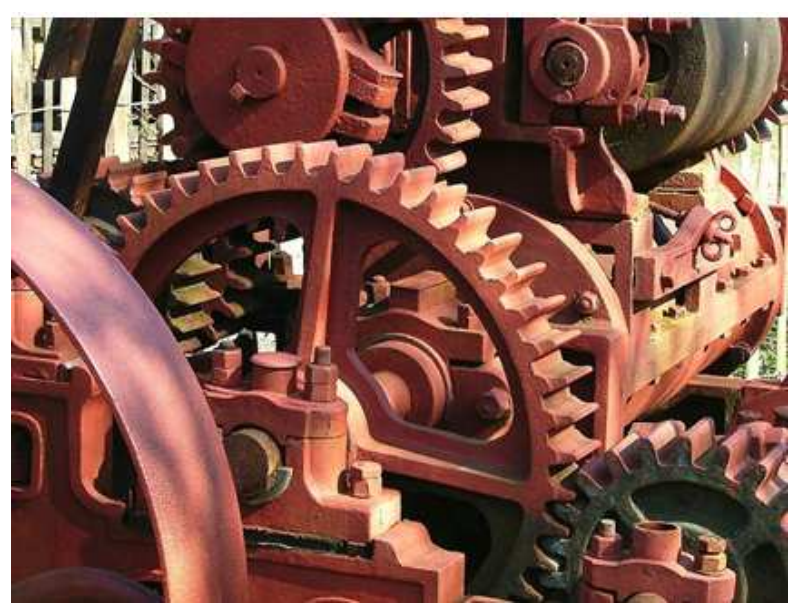

Fig. 2. Gears of a crushing plant

It is also equal to the ratio of the spokes and, a fortiori, the diameters of the wheels (to the nearest sign).

For transmissions with a large spacing, with regard to the dimension of the parts, a chain, a belt or a cascade of gears will be preferred.

In Fig. 2 one can see the gears of a crushing plant.

There are several types of teeth with special properties.

Almost all forms are said to be conjugate: During the rotation, the teeth remain in contact in a sagittal plane and when the geometrical locus of this point of contact is a straight line, the profiles of the teeth are circle developers.

A notable exception is the "Novikov" gear, also sometimes referred to as "Fisher", in which the contact between two teeth occurs during a "point" time all along the profile.

This is the almost universal profile used for power transmission.
The promoter of the circle is the trajectory of a point of a line which rolls without sliding on a circle. This circle is called a "base circle", of diameter db. $\left(=d_{\text {primitive }} \cos (\alpha)\right)$. The zone of existence of the involute lies between the base circle and the infinite.

There is no introducer inside the base circle. It is therefore not necessary to try to operate a gear inside the basic circles of the teeth which constitute it.

If one considers two basic circles associated with two wheels of the same gear, it is possible to roll without rolling a straight line simultaneously on the two circles. Hence the circumferential speed of the points of the circles is the same as those of the line.

A point on the line (point of meshing) will generate, on both sprockets, the tooth flank.

In the Fig. 3 can be seen a demonstration of the point of contact between the teeth.

If the line passes between the centers of the circles, the conventional gear is obtained.

The wheels then rotate in opposite directions and the transmission ratio depends on the diameters.

When it is outside, the gear is said to be paradoxical and the wheels turn in the same direction.

In the case of the conventional gear and more particularly of the standard gears, the basic circles are brought together so that the inside line forms an angle of pressure $\alpha$ with the perpendicular to the line passing through the axes. According to the standard, $\alpha$ is $20^{\circ}$ in Europe, $25^{\circ}$ in the US and $14.5^{\circ}$ in the old gears.

The teeth are limited to an area around point I, known as the "meshing point", where the sliding velocities of the teeth are tiny, which contributes to optimal gear performance.

The two tooth flanks are obtained by considering the two inner tangents.

The force exerted from one tooth to the other is divided into two: A tangential (useful) which transmits the torque and a radial (parasitic) which tends to move the wheels away (Mirsayar et al., 2017).

A small pressure angle to the advantage of limiting this parasitic repulsion force, but gives a fragile tooth shape.

On the contrary, a high pressure angle produces stubby teeth that are more resistant but generates a lot of forces on the axes.

One can drawing a tooth by profiling circle (parametric equation; see the Fig. 4).

The paradoxical gear is a two-wheel gear rotating in the same direction.

It is used in certain differentials (like the differential Mercier, engineer at Renault).

The high relative sliding speeds on the teeth allow partial "locking" of the differential when the wheels of the vehicle do not have the same grip on the ground.

This is not strictly speaking blockage since the resistance to movement is not obtained by obstacle but by friction. 


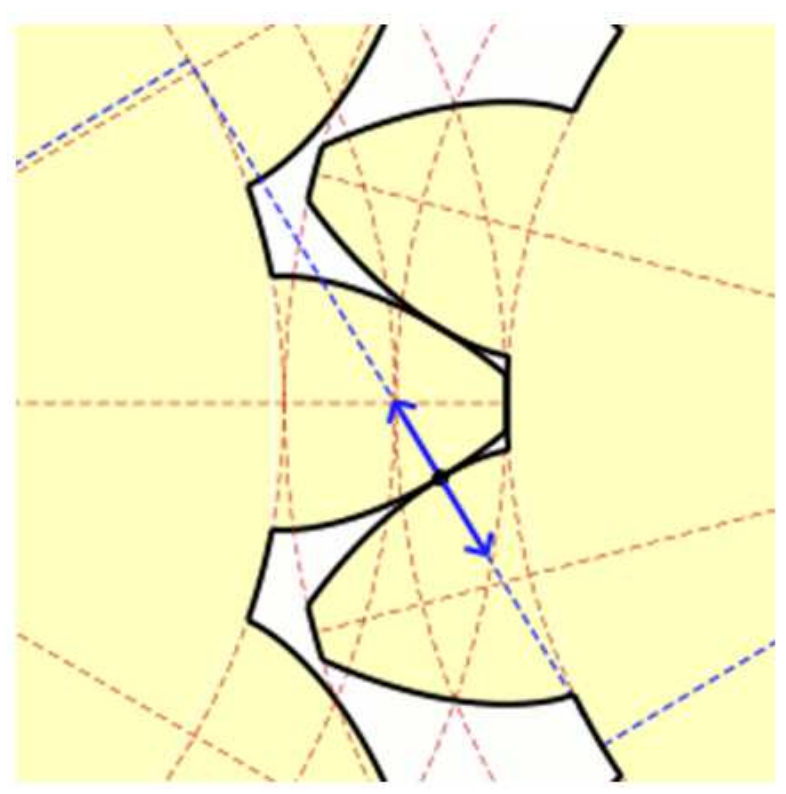

Fig. 3. Demonstration of the point of contact between the teeth

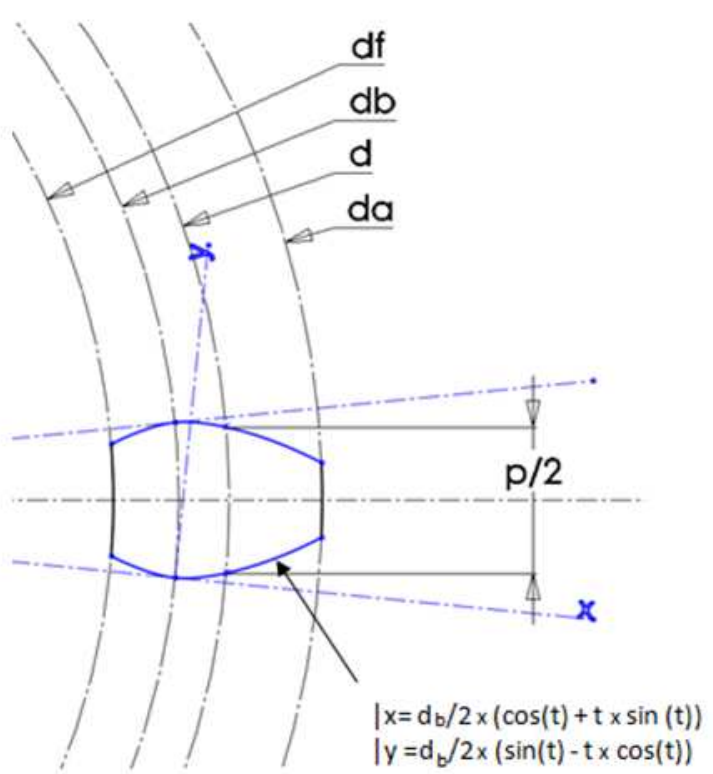

Fig. 4. Drawing of a tooth by profiling circle (parametric equation)

It is often necessary to arrange the teeth in different radial planes, or to use a helical tooth (continuous solution) to ensure relaying the teeth (Fig. 5).

The shape generator of the teeth is a straight line parallel to the axis of rotation. This is the most common type of teeth. It is used in all general mechanical applications. Indeed, it is the system that allows to transmit the maximum of effort. Nevertheless, its main flaw is being noisy.

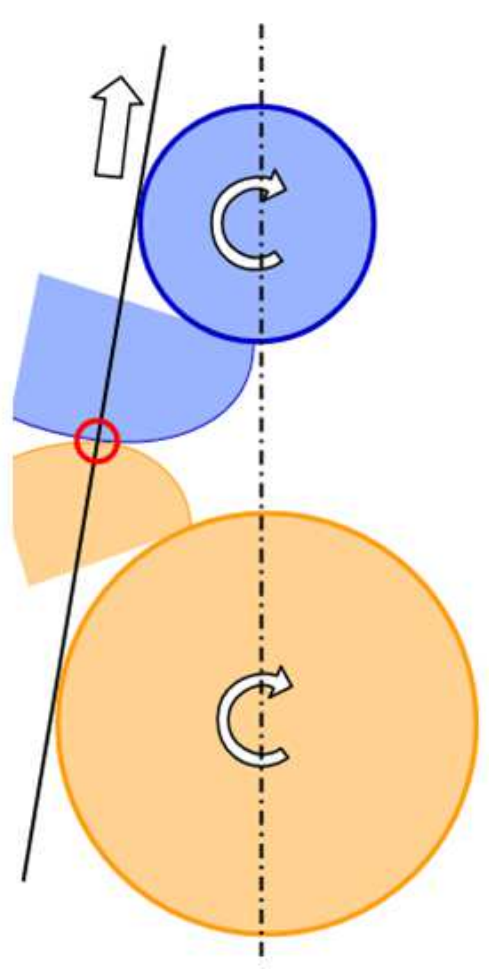

Fig. 5. The paradoxical gear is a two-wheel gear rotating in the same direction

The shape generator of the teeth is a helical line with the same axis as the axis of rotation. This type of toothing has the advantage of being quieter than the straight toothing, creating less vibration. The helical teeth also make it possible to increase the driving of the transmission by making the number of teeth simultaneously in contact become constant, which makes it possible to transmit greater forces and especially to attenuate the vibrations and the noises.

In contrast, this type of toothing produces an axial force whose intensity depends on the angle of inclination of the toothing. effort.

The bearings or bearings must be sized to resume this

For gears with parallel axes, the helices must be in opposite directions so that the teeth can engage, except in the very particular case of the paradoxical gear.

Figure 6 shows straight teeth and helical teeth. The three sprockets have the same apparent module and the two big wheels the same number of teeth.

Herringbone teeth, or "Citroën" teeth, are made up of two helical teeth of identical dimensions but of helices in opposite directions so as to cancel the axial force on the assembly (Fig. 7).

Although it is theoretically attractive, this type of toothing is in practice complicated to realize when the profile is not disengaging at the intersection of the two helices. 


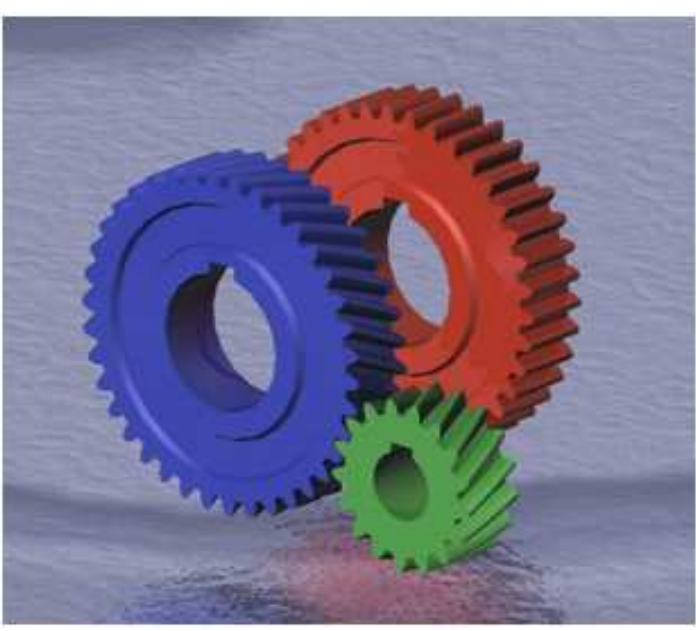

Fig. 6. Straight teeth and helical teeth. The three sprockets have the same apparent module and the two big wheels the same number of teeth

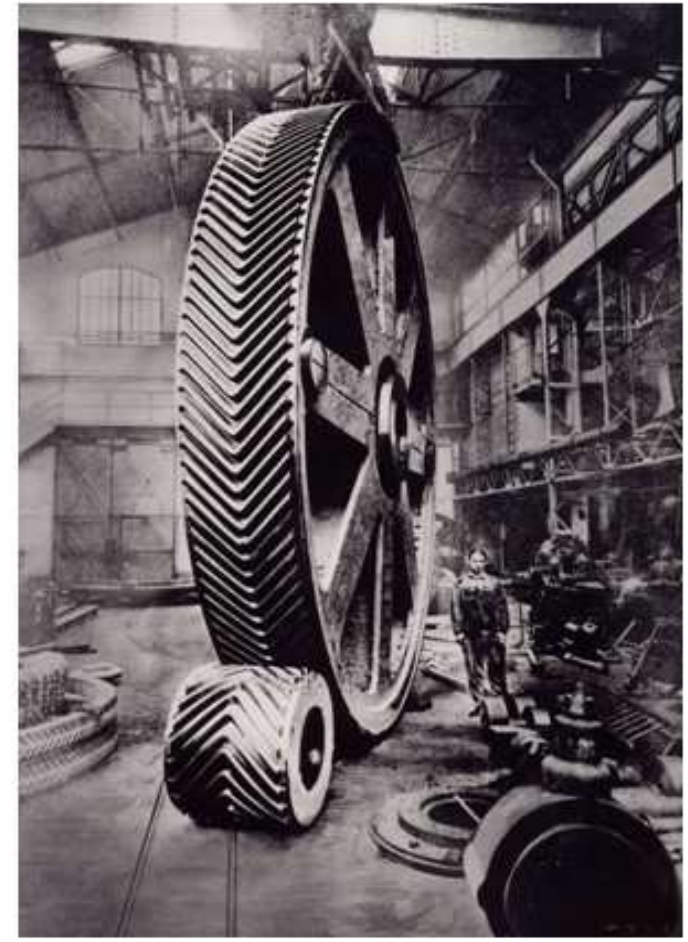

Fig. 7. V-shaped chevron gears from André Citroën, now emblem and logo of Citroën cars

It is therefore dear to achieve. Some manufacturers machine a central groove to allow easy removal of the cutting tools at the intersection of the two propellers. Herringbone teeth are only used in heavy industry.

In this case, it is often two gears with opposing propellers associated and more rarely one-piece sprockets (Gear, from Wikipedia).

A worm gear is a left-hand gear consisting of a worm and a conjugate worm wheel, called "worm wheel".
The profile of the screw is generally trapezoidal.

In many cases, this device is "irreversible", which means that if the screw can drive the wheel, the wheel can't cause, because of the friction and the angle of the screw propeller, this.

This aspect is particularly interesting for controlling a winch that can't be carried out by itself. Its role as speed reducer is also very interesting, because it allows a very high rotation ratio with only two elements and this in a reduced space and with a $90^{\circ}$ angle return at the price of a yield much lower than that of a conical gear.

It is, moreover, this poor performance which enables it, under certain conditions, to ensure irreversibility (Mirsayar et al., 2017).

The rack and pinion system is mainly used to transform a rotary motion into a translational movement or the opposite. It consists of a toothed wheel (Pinion) and a bar also toothed (rack). The toothed wheel, by turning, drives the teeth of the bar which then moves in translation. This mechanism is commonly used in automotive steering systems.

\section{Geometry of Basic Elements of a Cylindrical Gear with Straight Teeth}

The geometry elements of one toothed wheel and one gearing can be pursued in Fig. 8 (according to international standards).

\section{Determining the Momentary Dynamic (Mechanical) Efficiency, the Forces of the Gearing and the Velocities}

The forces, velocities, powers and efficiency can be obtained with the relationships 1-6; the forces from gearing may be seen in the Fig. 9:

$\left\{\begin{array}{l}F_{\tau}=F_{m} \cdot \cos \alpha_{1} \\ F_{\psi}=F_{m} \cdot \sin \alpha_{1} \\ v_{2}=v_{1} \cdot \cos \alpha_{1} \\ v_{12}=v_{1} \cdot \sin \alpha_{1} \\ \bar{F}_{m}=\bar{F}_{\tau}+\bar{F}_{\psi} \\ \bar{v}_{1}=\bar{v}_{2}+\bar{v}_{12}\end{array}\right.$

Where:

$F_{m}=$ The motive force (the driving force)

$F_{\tau}=$ The transmitted force (the useful force)

$F \psi=$ The slide force (the lost force)

$v_{1}=$ The velocity of element 1 , or the speed of wheel 1 (the driving wheel)

$v_{2}=$ The velocity of element 2 , or the speed of wheel 2 (the driven wheel)

$v_{12}=$ The relative speed of the wheel 1 in relation with the wheel 2 (this is a sliding speed) 

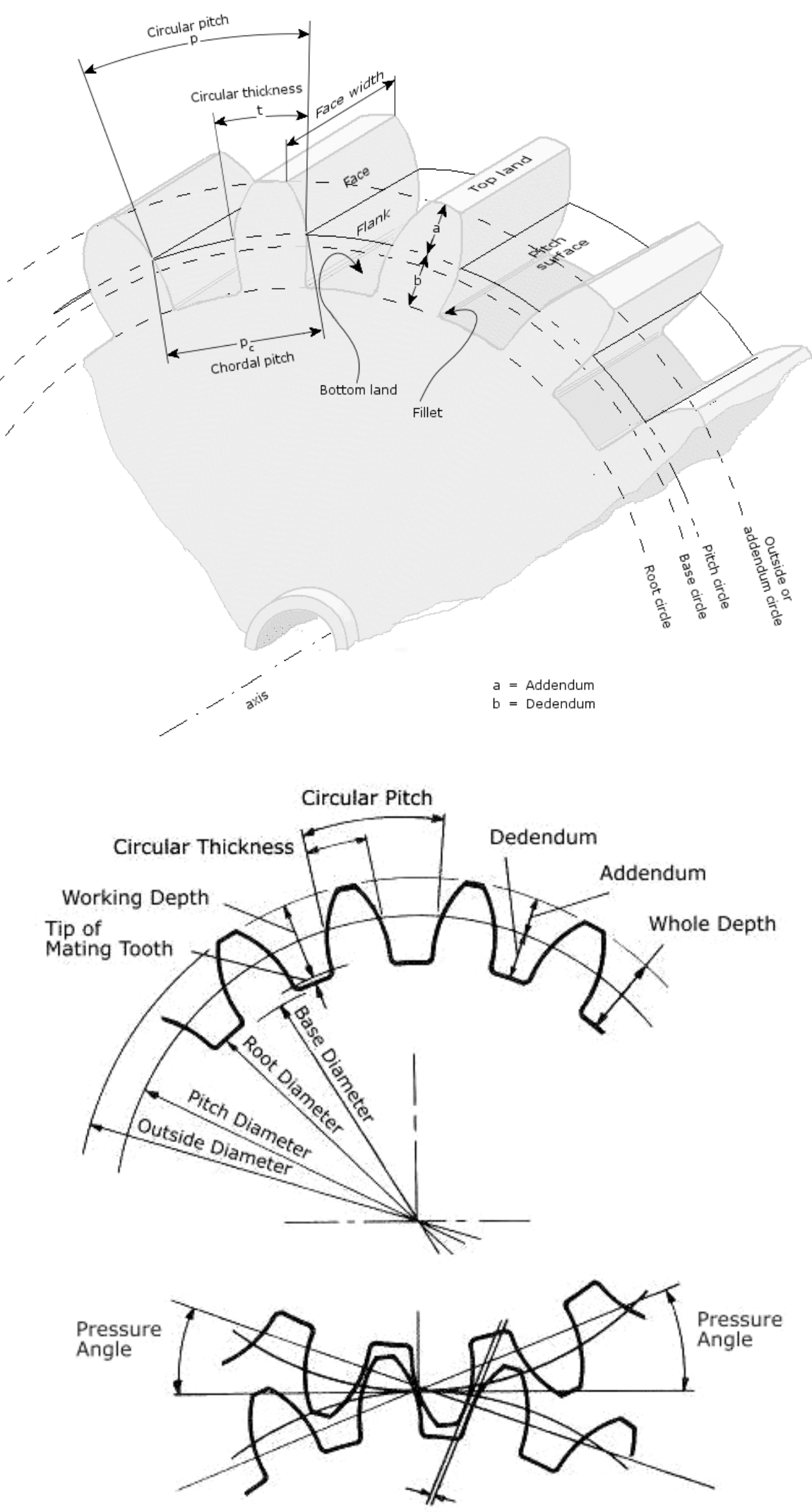

Fig. 8. Geometry elements of one toothed wheel and one gearing 


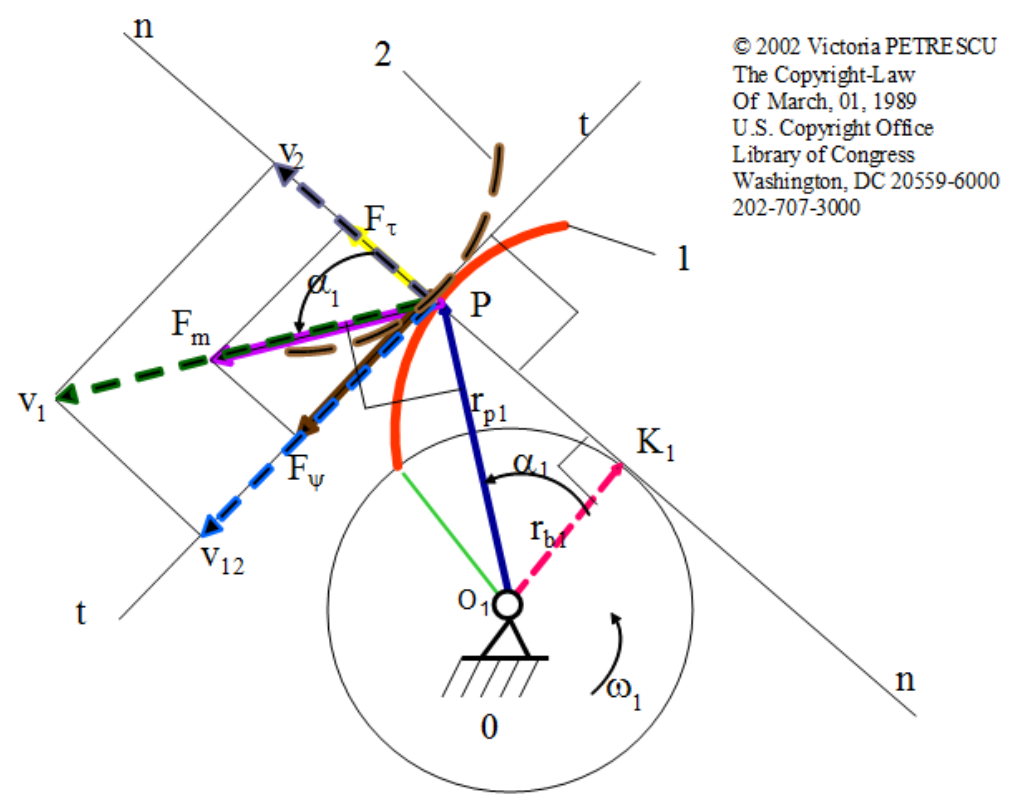

Fig. 9. The forces and the velocities of the gearing

The consumed power (in this case the driving power):

$P_{c} \equiv P_{m}=F_{m} \cdot v_{1}$

The useful power (the transmitted power from the profile 1 to the profile 2) will be written:

$P_{u} \equiv P_{\tau}=F_{\tau} \cdot v_{2}=F_{m} \cdot v_{1} \cdot \cos ^{2} \alpha_{1}$

The lost power will be written:

$P_{\psi}=F_{\psi} \cdot v_{12}=F_{m} \cdot v_{1} \cdot \sin ^{2} \alpha_{1}$

The momentary efficiency of couple will be calculated directly with the next relation:

$\left\{\begin{array}{l}\eta_{i}=\frac{P_{u}}{P_{c}} \equiv \frac{P_{\tau}}{P_{m}}=\frac{F_{m} \cdot v_{1} \cdot \cos ^{2} \alpha_{1}}{F_{m} \cdot v_{1}} \\ \eta_{i}=\cos ^{2} \alpha_{1}\end{array}\right.$

The momentary losing coefficient (Petrescu, 2012), will be written:

$\left\{\begin{array}{l}\psi_{i}=\frac{P_{\psi}}{P_{m}}=\frac{F_{m} \cdot v_{1} \cdot \sin ^{2} \alpha_{1}}{F_{m} \cdot v_{1}}=\sin ^{2} \alpha_{1} \\ \eta_{i}+\psi_{i}=\cos ^{2} \alpha_{1}+\sin ^{2} \alpha_{1}=1\end{array}\right.$

It can easily see that the sum of the momentary efficiency and the momentary losing coefficient is 1 . gear.

Now, one can determine the geometrical elements of
These elements will be used in determining the couple efficiency, $\eta$.

\section{Geometrical Elements of the Gear}

We can determine the next geometrical elements of the external gear, (for the right teeth, $\beta=0$ ), (Petrescu, 2012; Mirsayar et al., 2017).

The radius of the basic circle of the wheel 1 (of the driving wheel), (7):

$r_{b 1}=\frac{1}{2} \cdot m \cdot z_{1} \cdot \cos \alpha_{0}$

The radius of the outside circle of wheel $1(8)$ :

$r_{a 1}=\frac{1}{2} \cdot\left(m \cdot z_{1}+2 \cdot m\right)=\frac{m}{2} \cdot\left(z_{1}+2\right)$

It determines now the maximum pressure angle of the gear (9):

$\cos \alpha_{1 M}=\frac{r_{b 1}}{r_{a 1}}=\frac{\frac{1}{2} \cdot m \cdot z_{1} \cdot \cos \alpha_{0}}{\frac{1}{2} \cdot m \cdot\left(z_{1}+2\right)}=\frac{z_{1} \cdot \cos \alpha_{0}}{z_{1}+2}$

And now one determines the same parameters for the wheel 2, the radius of basic circle (10) and the radius of the outside circle (11) for the wheel 2 :

$r_{b 2}=\frac{1}{2} \cdot m \cdot z_{2} \cdot \cos \alpha_{0}$ 


$$
r_{a 2}=\frac{m}{2} \cdot\left(z_{2}+2\right)
$$

Now it can determine the minimum pressure angle of the external gear $(12,13)$ :

$$
\begin{aligned}
& \int \operatorname{tg} \alpha_{1 m}=\frac{N}{r_{b 1}} \\
& N=\left(r_{b 1}+r_{b 2}\right) \cdot \operatorname{tg} \alpha_{0}-\sqrt{r_{a 2}^{2}-r_{b 2}^{2}} \\
& =\frac{1}{2} \cdot m \cdot\left(z_{1}+z_{2}\right) \cdot \sin \alpha_{0} \\
& -\frac{m}{2} \cdot \sqrt{\left(z_{2}+2\right)^{2}-z_{2}^{2} \cdot \cos ^{2} \alpha_{0}} \\
& =\frac{m}{2} \cdot\left[\left(z_{1}+z_{2}\right) \cdot \sin \alpha_{0}\right. \\
& \left.-\sqrt{z_{2}^{2} \cdot \sin ^{2} \alpha_{0}+4 \cdot z_{2}+4}\right] \\
& \operatorname{tg} \alpha_{1 m}=\left[\left(z_{1}+z_{2}\right) \cdot \sin \alpha_{0}-\sqrt{z_{2}^{2} \cdot \sin ^{2} \alpha_{0}+4 \cdot z_{2}+4}\right] \\
& /\left(z_{1} \cdot \cos \alpha_{0}\right)
\end{aligned}
$$

One determines, to the external gear, the minimum (13) and the maximum (9) angle of pressure, right teeth. When have external gear with bended teeth $(\beta \neq 0)$ it uses the relations (14, 15 and 16):

$$
\begin{aligned}
& \operatorname{tg} \alpha_{t}=\frac{\operatorname{tg} \alpha_{0}}{\cos \beta} \\
& \operatorname{tg} \alpha_{1 m}=\left[\left(z_{1}+z_{2}\right) \cdot \frac{\sin \alpha_{t}}{\cos \beta}-\right. \\
& \sqrt{\left.z_{2}^{2} \cdot \frac{\sin ^{2} \alpha_{t}}{\cos ^{2} \beta}+4 \cdot \frac{z_{2}}{\cos \beta}+4\right]} \cdot \frac{\cos \beta}{z_{1} \cdot \cos \alpha_{t}} \\
& \cos \alpha_{1 M}=\frac{\frac{z_{1} \cdot \cos \alpha_{t}}{\cos \beta}}{\frac{z_{1}}{\cos \beta}+2}
\end{aligned}
$$

When has internal gear with bended teeth $(\beta \neq 0)$ it uses the relations (14 with 17, 18-A, or with 19, 20-B):

When the Driving Wheel 1, Has External Teeth:

$$
\begin{aligned}
\operatorname{tg} \alpha_{1 m}= & {\left[\begin{array}{l}
\left(z_{1}-z_{2}\right) \cdot \frac{\sin \alpha_{t}}{\cos \beta} \\
+\sqrt{z_{2}^{2} \cdot \frac{\sin ^{2} \alpha_{t}}{\cos ^{2} \beta}-4 \cdot \frac{z_{2}}{\cos \beta}+4}
\end{array}\right] \cdot \frac{\cos \beta}{z_{1} \cdot \cos \alpha_{t}} } \\
\cos \alpha_{1 M}= & \frac{\frac{z_{1} \cdot \cos \alpha_{t}}{\cos \beta}}{\frac{z_{1}}{\cos \beta}+2}
\end{aligned}
$$

When the Driving Wheel 1, Have Internal Teeth:

$$
\begin{aligned}
\operatorname{tg} \alpha_{1 M}= & {\left[\begin{array}{l}
\left(z_{1}-z_{2}\right) \cdot \frac{\sin \alpha_{t}}{\cos \beta} \\
+\sqrt{z_{2}^{2} \cdot \frac{\sin ^{2} \alpha_{t}}{\cos ^{2} \beta}+4 \cdot \frac{z_{2}}{\cos \beta}+4}
\end{array}\right] \cdot \frac{\cos \beta}{z_{1} \cdot \cos \alpha_{t}} } \\
\cos \alpha_{1 m}= & \frac{\frac{z_{1} \cdot \cos \alpha_{t}}{\cos \beta}}{\frac{z_{1}}{\cos \beta}-2}
\end{aligned}
$$

\section{Determining the Efficiency of the Gear}

The efficiency of the tools will be calculated by the integration of the efficiency of the time on all sections of the gearing of movement, namely from the minimum angle of the pressure to the maximum angle of pressure, the relationship (21), (Petrescu, 2012):

$$
\begin{aligned}
& \eta=\frac{1}{\Delta \alpha} \cdot \int_{a_{m}}^{\alpha_{M}} \eta_{i} \cdot d \alpha=\frac{1}{\Delta \alpha} \int_{\alpha_{m}}^{\alpha_{M}} \cos ^{2} \alpha \cdot d \alpha \\
& =\frac{1}{2 \cdot \Delta \alpha} \cdot\left[\frac{1}{2} \cdot \sin (2 \cdot \alpha)+\alpha\right]_{\alpha_{m}}^{\alpha_{M}} \\
& =\frac{1}{2 \cdot \Delta \alpha}\left[\frac{\sin \left(2 \alpha_{M}\right)-\sin \left(2 \alpha_{m}\right)}{2}+\Delta \alpha\right] \\
& =\frac{\sin \left(2 \cdot \alpha_{M}\right)-\sin \left(2 \cdot \alpha_{m}\right)}{4 \cdot\left(\alpha_{M}-\alpha_{m}\right)}+0.5
\end{aligned}
$$

\section{External and Internal Gearing}

The outer gear are the most common, not for that it would be best, but because they are more easily designed and constructed (Fig. 10). The internal gearing can be more efficient and more reliable when they are projected in an appropriate manner (Fig. 11).

An external contact ratios between the profiles shall be made only from a single point, while at the internal gear contact between the profiles is done by coil between them (Fig. 12 (Petrescu, 2012)).

\section{Gears Synthesis to Avoid the Interferences}

To prevent this phenomenon of interference, A point should be between $\mathrm{C}$ and $\mathrm{K} 1$ (addendum circle of the wheel 2, $\mathrm{C}_{\mathrm{a} 2}$, must cut action line between points $\mathrm{C}$ and $\mathrm{K} 1$ and in no case does not exceed the point $\mathrm{K} 1$ ). In a similar way $\mathrm{C}_{\mathrm{a} 1}$ addendum circle must cut action line between points $\mathrm{C}$ and $\mathrm{K} 2$, resulting in point $\mathrm{E}$, which in no case, does not exceed the point $\mathrm{K} 2$. The conditions to prevent this phenomenon of interference can be written with the relations (22). The basic conditions of interference, are the same $\left(\mathrm{CA}<\mathrm{K}_{1} \mathrm{C} ; \mathrm{CE}<\mathrm{K}_{2} \mathrm{C}\right)$, but the originality of this new methods presented consists in the way in which has been solved the relationship fever (see the System 22) (Petrescu, 2012), (Fig. 13): 


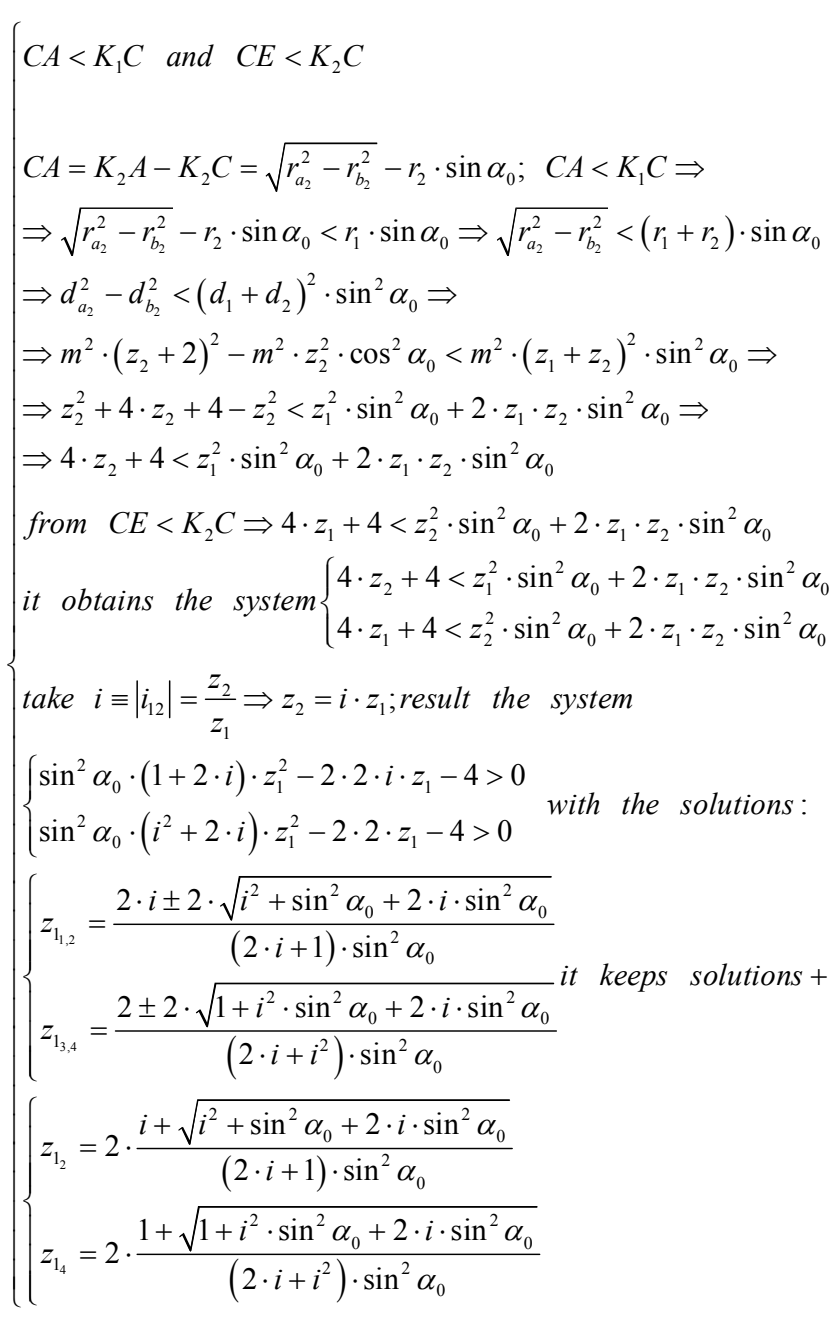

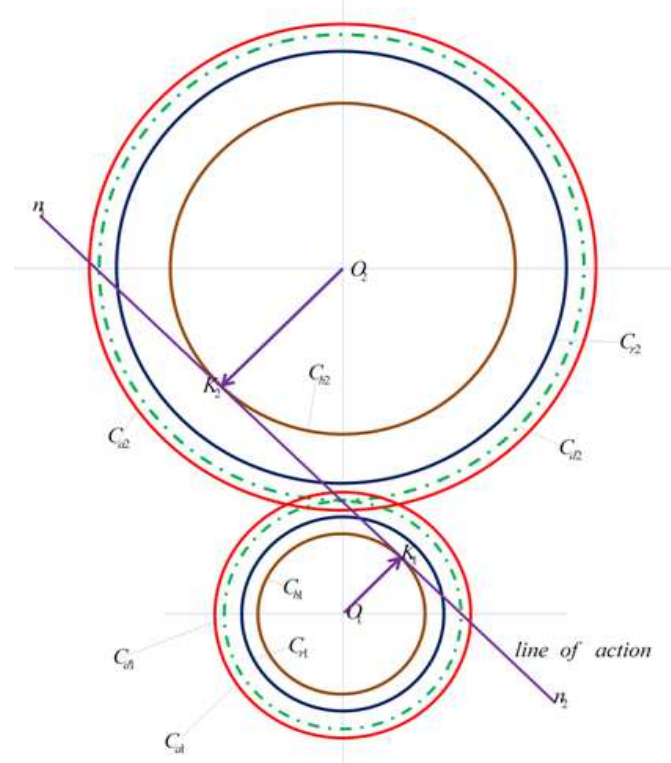

Fig. 10. An external gearing

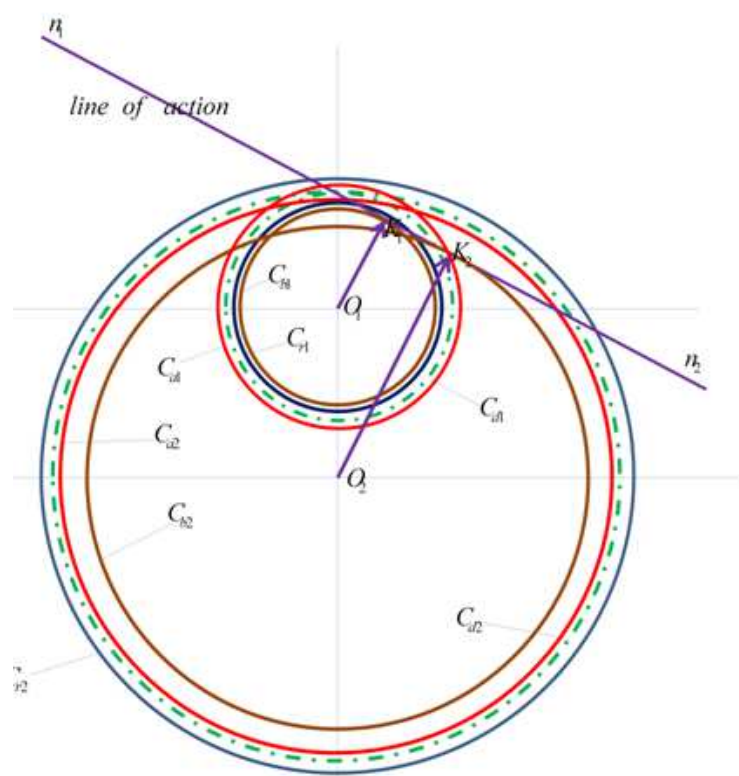

Fig. 11. An internal gearing 


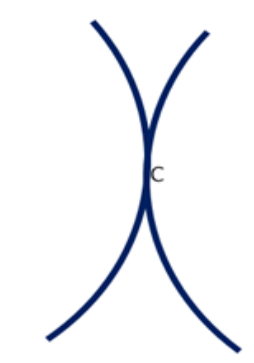

External gearing

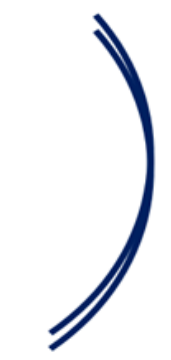

Internal gearing
Fig. 12. Contact between profiles

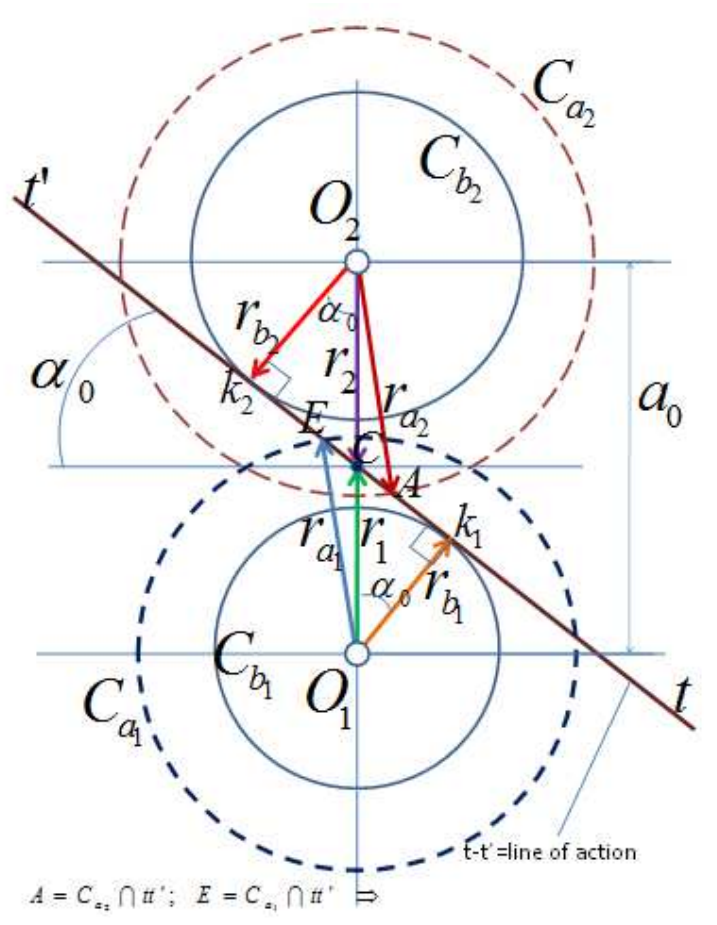

Fig. 13. Line of action (t-t') at an external gearing

The relationship that generates always gives values lower than the relationship that generates this is sufficient condition (23) for the identification of the minimum number of teeth of the wheel 1 , necessary to avoid interference (Petrescu, 2012):

$z_{\text {min }} \equiv z_{1_{2}}=2 \cdot \frac{i+\sqrt{i^{2}+\sin ^{2} \alpha_{0}+2 \cdot i \cdot \sin ^{2} \alpha_{0}}}{(2 \cdot i+1) \cdot \sin ^{2} \alpha_{0}}$

When we have inclined teeth, one takes $z_{\min } \rightarrow z_{\min } / \cos \beta$ and $\alpha_{0} \rightarrow \alpha_{0 t}$ and the relationship (23) takes the form (24).

The minimum number of teeth of the driving wheel 1 , is a function on some parameters: The pressure angle (normal on the pitch circle, $\alpha_{0}$ ), the tooth inclination angle $(\beta)$ and the transmission ratio $(i=$ $\left|i_{12}\right|=\left|-z_{2} / z_{1}\right|=z_{2} / z_{1}$ ), (see the relationship 24 and (Maros, 1958; Stoica, 1977):

$$
\left\{\begin{array}{l}
z_{\text {min }} \equiv z_{\mathrm{l}_{2}}=2 \cdot \cos \beta \cdot \frac{i+\sqrt{i^{2}+\sin ^{2} \alpha_{0 t}+2 \cdot i \cdot \sin ^{2} \alpha_{0 t}}}{(2 \cdot i+1) \cdot \sin ^{2} \alpha_{0 t}} \\
\text { where: } \operatorname{tg} \alpha_{0 t}=\frac{\operatorname{tg} \alpha_{0}}{\cos \beta} \Rightarrow \\
\Rightarrow \alpha_{0 t}=\operatorname{arctg}\left(\frac{\operatorname{tg} \alpha_{0}}{\cos \beta}\right)
\end{array}\right.
$$

The system (24) is a simple, uniform and general relationship which can give the solutions for a minimum number of teeth of the wheel 1 (drive wheel) to prevent interference. In the tables from Fig. $14-28$ is chosen a value alpha 0 (35 [degree]) and gradually increase in value of the angular beta (from 0 $\left.\left.{ }^{\circ}\right] 40\left[^{\circ}\right]\right)$ and the transmission ratio $i$ (1 to 80$)$ and one receives the minimum number of teeth. Then we will gradually decrease the value of the alpha0 angle (at 35 [degree] to $5\left[^{\circ}\right]$ ).

The inner shaft on the condition that they avoid interference is the same as the external gear (the relationship 24).

Moreover, he can write and the condition of the existence of the wheel with the internal teeth systems (25 and 26):

$$
\left\{\begin{array}{l}
r_{a_{2}}>r_{b_{2}} \Rightarrow \frac{m}{2} \cdot\left(\frac{z_{2}}{\cos \beta}-2\right)>\frac{m}{2} \cdot \frac{z_{2}}{\cos \beta} \cdot \cos \alpha_{0 t} \\
\Rightarrow \frac{z_{2}}{\cos \beta}-2>\frac{z_{2}}{\cos \beta} \cdot \cos \alpha_{0 t} \Rightarrow z_{2}>\frac{2 \cdot \cos \beta}{1-\cos \alpha_{0 t}}
\end{array}\right.
$$

$$
\left\{\begin{array}{l}
z_{2}>\frac{2 \cdot \cos \beta}{1-\cos \alpha_{0 t}} \\
\cos \alpha_{0 t}=\frac{1}{\sqrt{1+\operatorname{tg}^{2} \alpha_{0 t}}}=\frac{1}{\sqrt{1+\frac{\operatorname{tg}^{2} \alpha_{0}}{\cos ^{2} \beta}}}=\frac{\cos \beta}{\sqrt{\cos ^{2} \beta+\operatorname{tg}^{2} \alpha_{0}}} \\
\Rightarrow z_{2}>\frac{2 \cdot \cos \beta}{1-\frac{\cos \beta}{\sqrt{\cos ^{2} \beta+\operatorname{tg}^{2} \alpha_{0}}} \Rightarrow z_{2}}>\frac{2 \cdot \cos \beta \cdot \sqrt{\cos ^{2} \beta+\operatorname{tg}^{2} \alpha_{0}}}{\sqrt{\cos ^{2} \beta+\operatorname{tg}^{2} \alpha_{0}}-\cos \beta} \\
\Rightarrow z_{2}>\frac{2 \cdot \cos \beta \cdot \sqrt{\cos ^{2} \beta+\operatorname{tg}^{2} \alpha_{0}} \cdot\left(\sqrt{\cos ^{2} \beta+\operatorname{tg}^{2} \alpha_{0}}+\cos \beta\right)}{z_{2}>\frac{2 \cdot \cos \beta}{\operatorname{tg}^{2} \alpha_{0}} \cdot\left(\cos ^{2} \beta+\operatorname{tg}^{2} \alpha_{0}+\cos ^{2} \cdot \sqrt{\cos ^{2} \beta+\operatorname{tg}^{2} \alpha_{0}}\right)} \\
\Rightarrow z_{2}>\frac{2 \cdot \cos ^{3} \beta}{\operatorname{tg}^{2} \alpha_{0}} \cdot\left(1+\frac{\operatorname{tg}^{2} \alpha_{0}}{\cos ^{2} \beta}+\sqrt{1+\frac{\operatorname{tg}^{2} \alpha_{0}}{\cos ^{2} \beta}}\right)
\end{array}\right.
$$




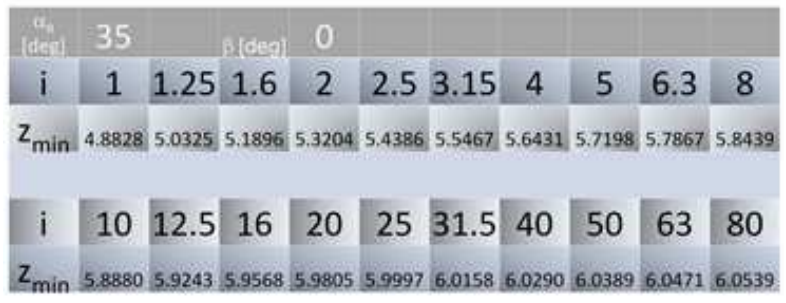

Fig. 14. $\alpha_{0}=35[\mathrm{deg}], \beta=0[\mathrm{deg}]$

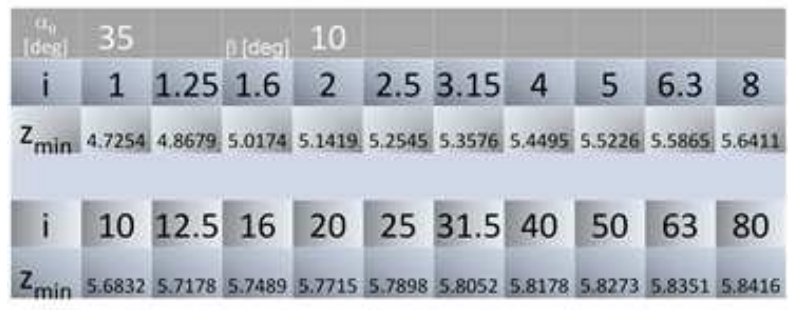

Fig. 15. $\alpha_{0}=35$ [deg], $\beta=10[\mathrm{deg}]$

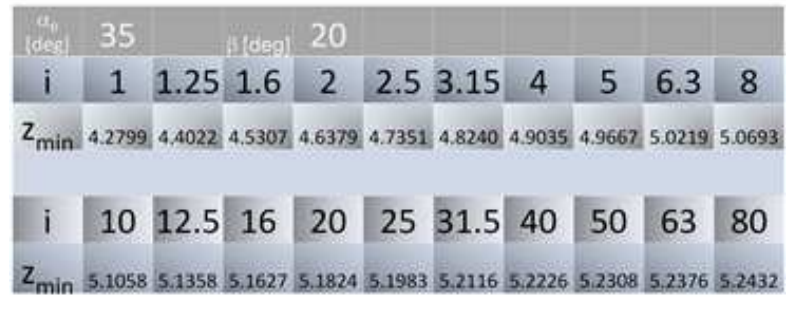

Fig. 16. $\alpha_{0}=35[\mathrm{deg}], \beta=20[\mathrm{deg}]$

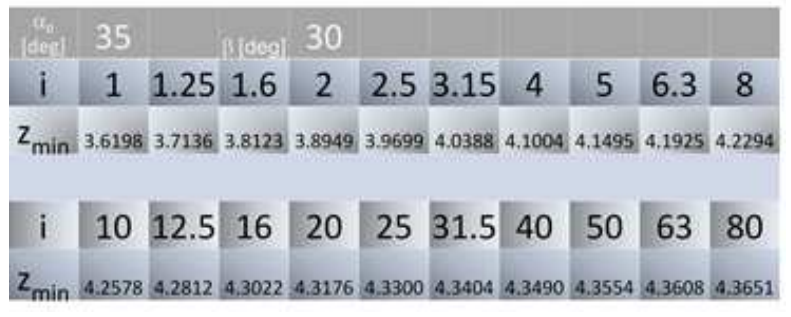

Fig. 17. $\alpha_{0}=35[\mathrm{deg}], \beta=30[\mathrm{deg}]$

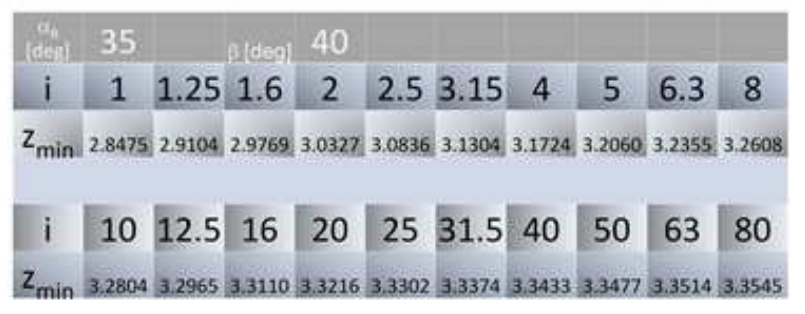

Fig. 18. $\alpha_{0}=35[\mathrm{deg}], \beta=40[\mathrm{deg}]$

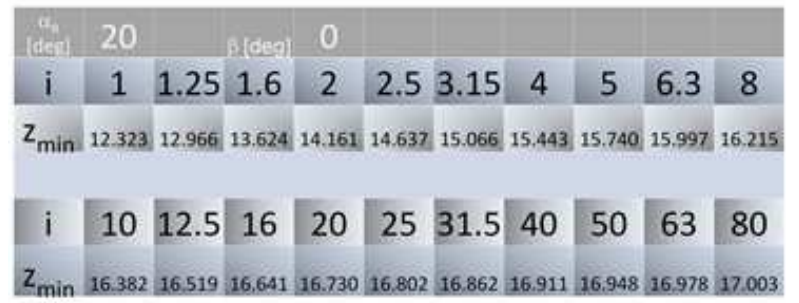

Fig. 19. $\alpha_{0}=20$ [deg], $\beta=0$ [deg]

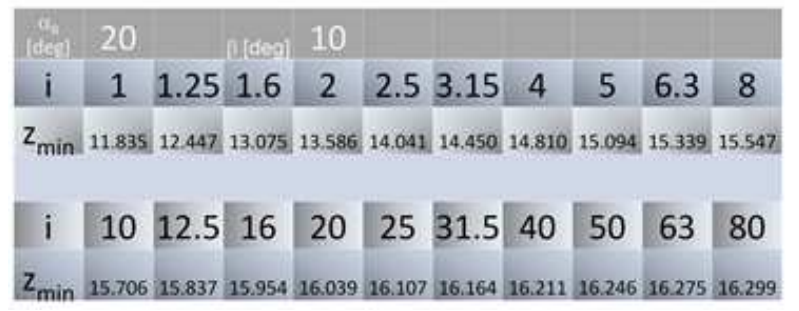

Fig. 20. $\alpha_{0}=20$ [deg], $\beta=10$ [deg]

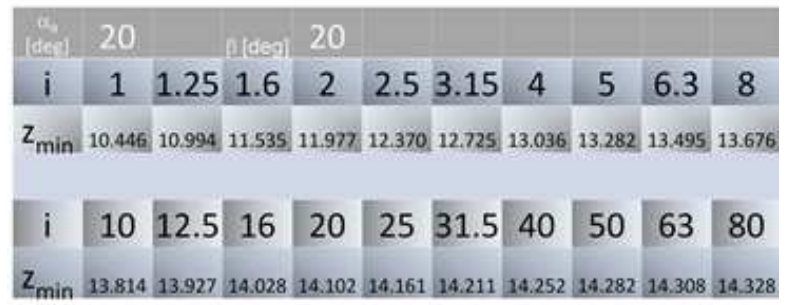

Fig. 21. $\alpha_{0}=20$ [deg], $\beta=20$ [deg]

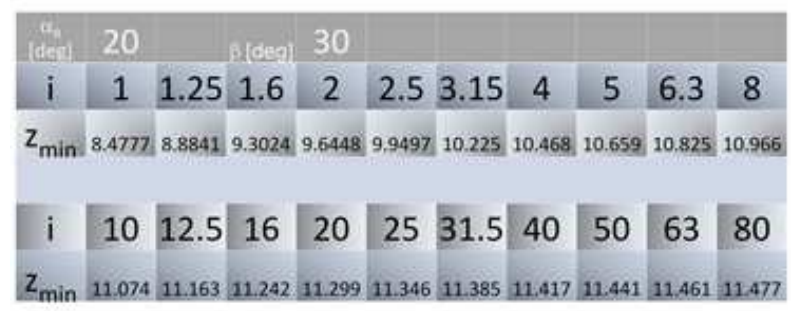

Fig. 22. $\alpha_{0}=20$ [deg], $\beta=30$ [deg]

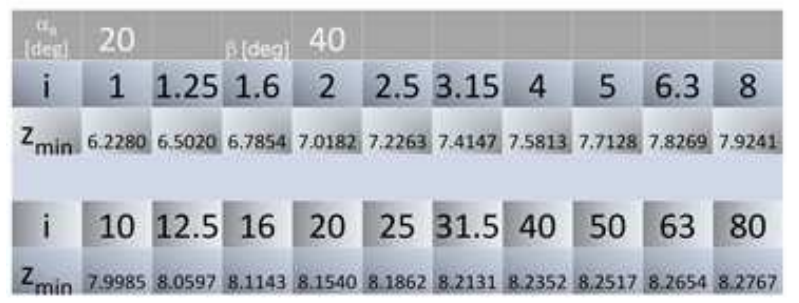

Fig. 23. $\alpha_{0}=20$ [deg], $\beta=40$ [deg] 


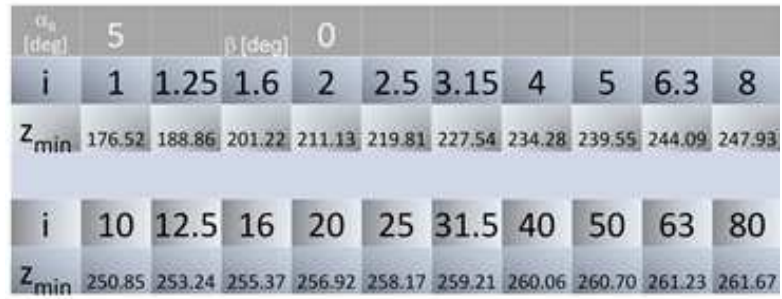

Fig. 24. $\alpha_{0}=5$ [deg], $\beta=0[\mathrm{deg}]$

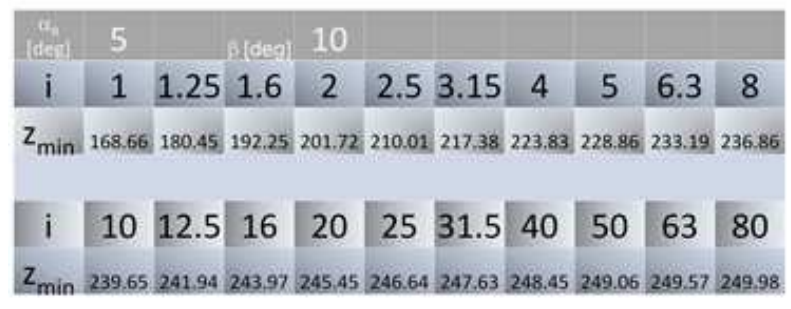

Fig. 25. $\alpha_{0}=5$ [deg], $\beta=10[\mathrm{deg}]$

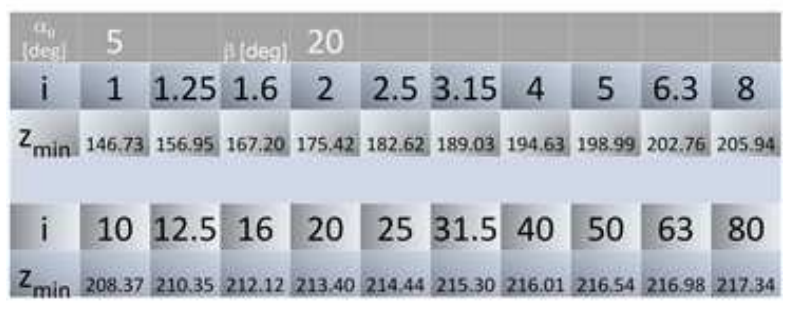

Fig. 26. $\alpha_{0}=5$ [deg], $\beta=20[\mathrm{deg}]$

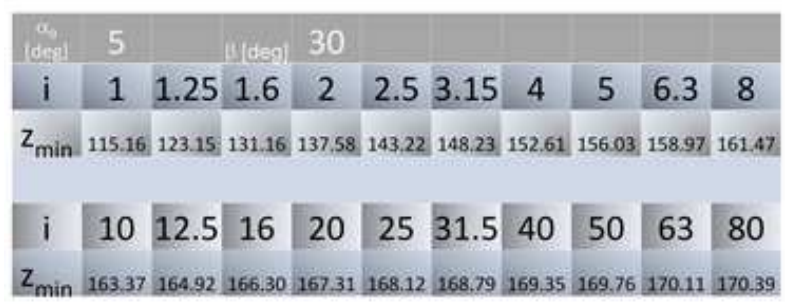

Fig. 27. $\alpha_{0}=5[\mathrm{deg}], \beta=30[\mathrm{deg}]$

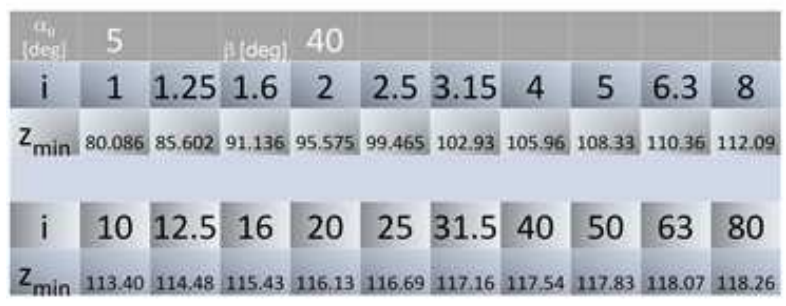

Fig. 28. $\alpha_{0}=5[\mathrm{deg}], \beta=40[\mathrm{deg}]$
They were used and additional relations (27):

$$
\left\{\begin{array}{l}
r_{1}=\frac{1}{2} m \cdot z_{1} ; \quad r_{2}=\frac{1}{2} m \cdot z_{2} ; \\
r_{b_{1}}=\frac{1}{2} m \cdot z_{1} \cdot \cos \alpha_{0} ; r_{b_{2}}=\frac{1}{2} m \cdot z_{2} \cdot \cos \alpha_{0} \\
r_{a_{1}}=r_{1}+m=\frac{1}{2} m \cdot z_{1}+\frac{2}{2} m=\frac{m}{2} \cdot\left(z_{1}+2\right) \\
r_{a_{2}}=r_{2}-m=\frac{1}{2} m \cdot z_{2}-\frac{2}{2} m=\frac{m}{2} \cdot\left(z_{2}-2\right) \\
r_{r_{1}}=r_{1}-1.25 m=\frac{1}{2} m \cdot z_{1}-\frac{2.5}{2} m=\frac{m}{2} \cdot\left(z_{1}-2.5\right) \\
r_{r_{2}}=r_{2}+1.25 m=\frac{1}{2} m \cdot z_{2}+\frac{2.5}{2} m=\frac{m}{2} \cdot\left(z_{2}+2.5\right)
\end{array}\right.
$$

\section{Results and Discussion}

The method given has the great advantage to optimize the number of teeth for a gear, prior to making the synthesis. In this way, the manufacturer may choose the minimum number of teeth for a transmission ratio, $i$.

Classic in order to achieve an $i=2$, the manufacturer may choose between 18 or 33 teeth on the drive wheel 1 , which means a 36 or 66-tooth driven wheel 2. Using the tables shown (Fig. 14-28), one can make a selection (Angelas and Lopez-Cajun, 1988; Xiao, 2011; Cao et al., 2011; Pelecudi et al., 1985; Petrescu and Petrescu, 2002; 2003; Petrescu et al., 2007; Rey, 2013; Stoica, 1977).

The engineer may be selected for the drive wheel 1 , a number of teeth $z_{1}=6$ with alpha $0=35\left[^{\circ}\right]$ and a beta $=$ $0\left[^{\circ}\right]$. He can do this not only for a transmission ratio $i=$ 2 , but also for the range of $i=1.25$ to $i=25$ (Fig. 14).

If he choose alpha $0=35\left[^{\circ}\right]$ and beta $=40\left[^{\circ}\right]$, then he can take a number of teeth on the wheel driving 1 of $z_{1}=4$ and can do this for the entire range from $i=2$ to $i=80$ (Fig. 18).

The manufacturer may do this when it is necessary to have a minimum number of teeth, but with the effectiveness of the mechanism of reduction.

Otherwise, when we want a highly efficient, should increase the number of teeth and reduce the alpha 0 angles and Beta site. With an alpha $0=5\left[^{\circ}\right]$ and beta $=0$ (Fig. 24), we can take the number of teeth on the steering wheel $1, z_{1}$ $=189$ (for $i=1.25)$, up to $Z_{1}=262$ (for $\left.i=80\right)$.

For known alpha classic $0=20\left[^{\circ}\right]$ and beta $=0\left[^{\circ}\right]$ when the report $i$ varies from 1 to $80, z_{1}$ takes values between 13 and 18 (Fig. 19). With the conventional method has been taken only the minimum value of 18 to the minimum number of teeth (Petrescu, 2012).

The method given manages to compile (in theory), the best parameters of option for any desired implement.

The relations shown have the great advantage to donate the best solutions for any situation you want, without the need for difficult calculations, construction experimental, or specialized software. All relations have 
been calculated and verified with the written programs in Excel (Angelas and Lopez-Cajun, 1988; Xiao, 2011; Cao et al., 2011; Pelecudi et al., 1985; Petrescu and Petrescu, 2002; 2003; Petrescu et al., 2007; Rey, 2013; Stoica, 1977).

Comparisons with a specialized software (US) has shown a precision (fitness) in perfect condition. Their work and procedures could be so much smaller.

Parallel drawn between software "Us Autodesk" and the relationship of calculation presented will be highlighted in the following paper (that handle a high volume), (Angelas and Lopez-Cajun, 1988; Xiao, 2011; Cao et al., 2011; Pelecudi et al., 1985; Petrescu and Petrescu, 2002; 2003; Petrescu et al., 2007; Rey, 2013; Stoica, 1977).

Applied in the automobile industry, the mechanisms for the transmission, these changes can reduce the total fuel consumption additional pollutant emissions.

The gears may be designed to operate without noise (Angelas and Lopez-Cajun, 1988; Xiao, 2011; Cao et al., 2011; Pelecudi et al., 1985; Petrescu and Petrescu, 2002; 2003; Petrescu et al., 2007; Rey, 2013; Stoica, 1977; Petrescu, 2012).

But, applications will be spectacular in automatic transmissions used in the aerospace, in robotics and mechatronics.

When the number of teeth on the wheels 1 increases, it may be possible to reduce the angle of normal pressure, alfa0. One will see that for $z_{1}=90$ may take less for the angle of normal pressure (for the angle of the reference pressure), $i=0$ to 80 . The yield increases when the number of teeth on the wheel driving $1, z_{1}$, increases as well and when the angle of pressure, alfa0 reduces; $z_{2}$ or $i_{12}$ are not so much influence on the value of the efficiency.

It can easily see that for alfa 0 value $=20^{\circ}$, yield takes approximately $\eta$ [ap] $=0.89$ value for all parameter values of others (this justifies the choice of this value alfa $=20^{\circ}$, for the angle of standard pressure of reference). $20^{0}$.

Best efficiency can be obtained only for an alfa $0 \neq$

But the angle of reference pressure, alfa0, may be reduced at the same time, the number of teeth on the wheel driving $1, z_{1}$ increases, to increase the efficiency of gears.

Otherwise, when we want to create a gear with a $z_{1}$ low (for a gauge less), will be required to increase the value of the alfa 0 , in order to ensure a positive values for $\alpha \mathrm{m}$ (in this case, the yield will be reduced).

The module of the gearbox, $\mathrm{m}$, does not have any influence on the value of the effectiveness of him. When alfa 0 is reduced can take out a normal mode of greater, for increasing the addendum of teeth, but increasing the module $\mathrm{m}$ at the same time with the increase in $z_{1}$ can lead to a gauge greater. The efficiency of the gears, $\eta$, there is indeed a function of alfa 0 and $z_{1}: \eta=\mathrm{f}\left(\mathrm{alfa} 0, z_{1}\right) ; \alpha m \alpha M$ and are only the parameters of the intermediaries.

For a good projection of tools, it is necessary a $z_{1}$ and $z_{2}$ greater than $30-60$; but this condition may increase the jig mechanism.

The best efficiency can be obtained with the inner drive when the drive wheel 1 is the ring; minimum efficiency will be obtained when the drive wheel 1 of the internal gearing has teeth (Petrescu, 2012).

For external drives, best efficiency is obtained when the wheel is more than driving wheel; when the normal reduce alfa0 angle, contact increases the report and increase efficiency, also.

The effectiveness of the measure also increases when the number of teeth of the drive wheel 1 increases (when the increase) $z_{1}$.

Optimization of this mechanism (the mechanism of gears), we can improve the functionality drives gear (Angelas and Lopez-Cajun, 1988; Xiao, 2011; Cao et al., 2011; Pelecudi et al., 1985; Petrescu and Petrescu, 2002; 2003; Petrescu and et al., 2007; Rey, 2013; Stoica, 1977).

The mechanisms for the transmission an important problem is the interference of the teeth.

To avoid interference between the teeth, you must know the minimum number of teeth of the drive wheel, depending on the angle of pressure (normal on the pitch circle Alpha0), depending on the tilt angle tooth (beta) and as a function of the transmission ratio $(i)$.

\section{Conclusion}

The gears are today the most widespread and most frequently used mechanical transmissions, all over the world.

They must be the factory on an industrial scale, everywhere and have a variety of uses, be extremely important for both heavy machines of industrial buildings, as well as for domestic appliances, electronics, etc. meet the size of the normal excessive, big or even huge (used from ships, heavy machines or in energy), but also for watches tools, or for devices of sizes micro.

The work of his wishes to make an overview of the toolbar and then an introduction to the study of their general and a study customized for gears with fixed.

The methods listed for the gears with fixed rate, can then be customized and used and the planetary gears (drive shaft with the shaft).

The work of the original components, very much, such as the front and the geometry, Forces, automatic gearbox, powers, outputs (Tools), which form part of the actual dynamics of the mechanisms and also the 
most important criterion in terms of performance of a mechanism.

Gears, broke today in all the fields of activity.

They have the advantage of working with very high efficiency. In addition, the gears can transmit heavy loads. Irrespective of their size, instruments should to be compiled taking into account the conditions carefully.

The work from the front is trying to present the main conditions which must be met in order to correct the synthesis of an instrument.

In accordance with the existing standards, a unit is defined as a mechanism for the basis of which consists of two elements of transmission (wheels, sectors or Toothed bar), being in rotation movement/translation absolute or relative, in which one of the components of the other acts by the action of the teeth, which are in contact in succession and continuously.

The gears or mechanisms with gears, are practically shift elements top (in general class fourth-C4), which are intended to transmit and or to transform the movement by reducing the speed of rotation (with increasing the moment), or by increasing the angular speed (with a decrease in the torque) from the entrance toward the exit, by maintaining the power approximately constant (with losses very small, mechanical and the friction, yields because of the large and extra large from which we speeds are).

The efficiency of the instruments shall be calculated by the integration of the effectiveness of the time on all the sections of the gears of movement, namely from the minimum angle of the pressure at the maximum angle of pressure.

Is sufficient condition to determine the minimum number of teeth of the wheel 1 , necessary to prevent interference.

\section{The Different Types of Gears}

\section{Straight Gears}

This type of gear makes it possible to transmit a rotational movement and the power between two parallel shafts.

This type of gear is classified by the shape and geometry of their teeth. Straight gears are characterized by standard values: A metric gear is mainly characterized by its modulus and number of teeth, $\S$ the article on the module. An Anglo-Saxon gear is mainly characterized by its pitch and number of teeth, $\S$ the article on the pitch.

\section{Straight Spur Gears}

Straight gears with straight teeth (Fig. 29).
These are the simplest and most economical gears, it is this type of gears that we find in the transmissions of our crawlers.

All faith, their operation induces shocks of meshing, which causes noise and vibration.

These defects can be reduced by reducing the modulus of the gears, but this also reduces their resistance.

Straight gears with helical teeth (Fig. 30).

Like the spur gears, they transmit rotational motion and power between two parallel shafts, but their teeth are tilted.

This configuration is more efficient and offers a greater progressivity and continuity of meshing, which allows to transmit more torque, while being quieter. They are however more complex to manufacture. In addition, the inclination of the teeth induces lateral forces which must be borne by the bearings of the gear. We find this type of gear in the transmission of our vehicles every day.

Straight toothed gear (Fig. 31).

It is a variant of straight gears with helical teeth, where the teeth form rafters.

This configuration, which is still somewhat more complex, makes it possible to cancel the lateral forces of the helical teeth whilst retaining their advantages.

The conical gears (Fig. 32).

The conical gears are used to transmit a rotational movement between two non-parallel shafts, usually perpendicular.

One finds this type of gears in the bridges of the shafty, the couple pinion/crown.

As with straight gears, there are different types of teeth (straight toothing, helical teeth) with the same advantages and disadvantages.

Worm gears (Fig. 33).

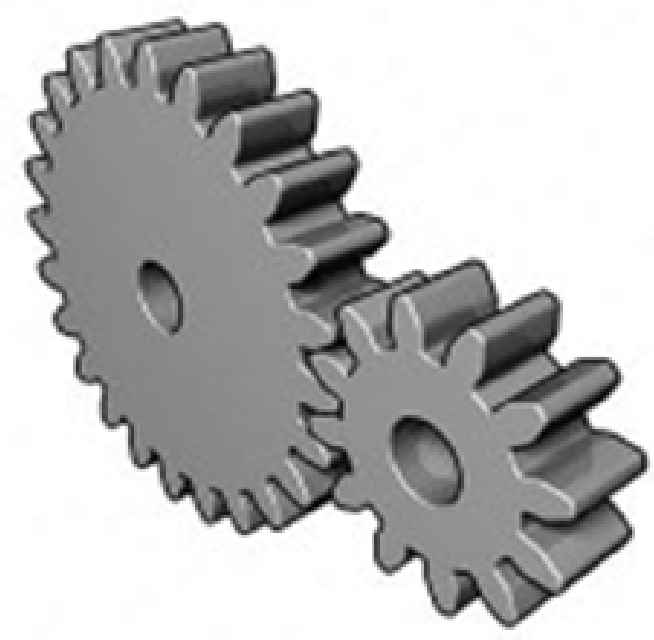

Fig. 29. Straight gears with straight teeth 

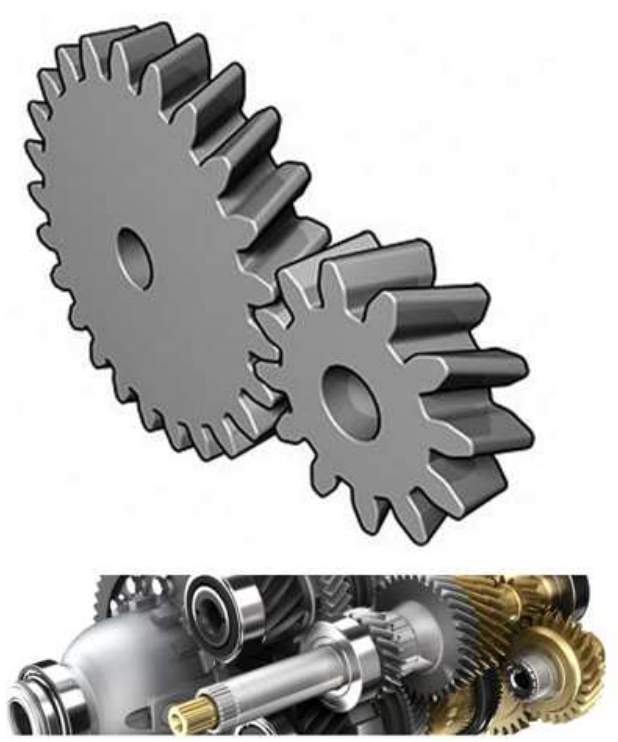

Fig. 30. Straight gears with helical teeth

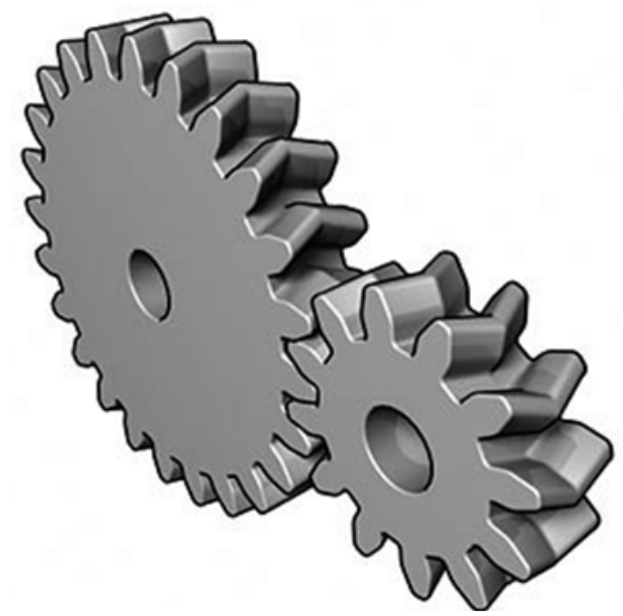

Fig. 31. Straight toothed gear

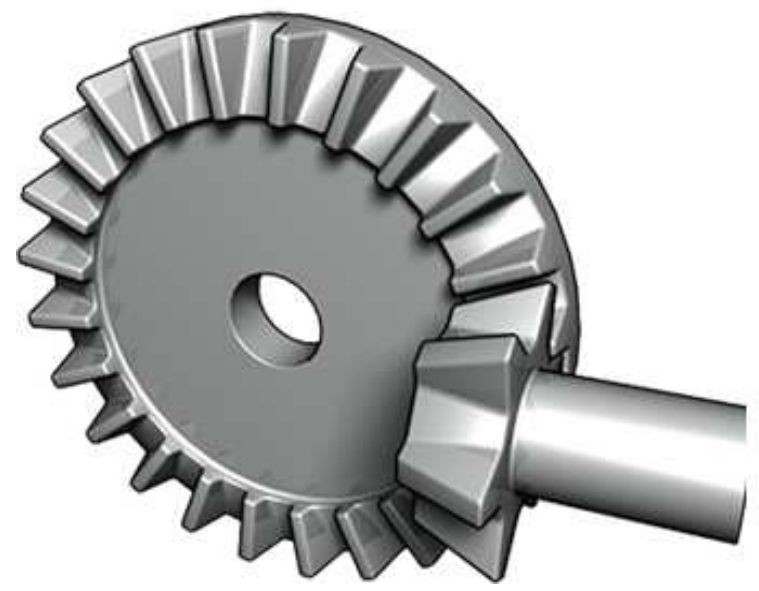

Fig. 32. The conical gears

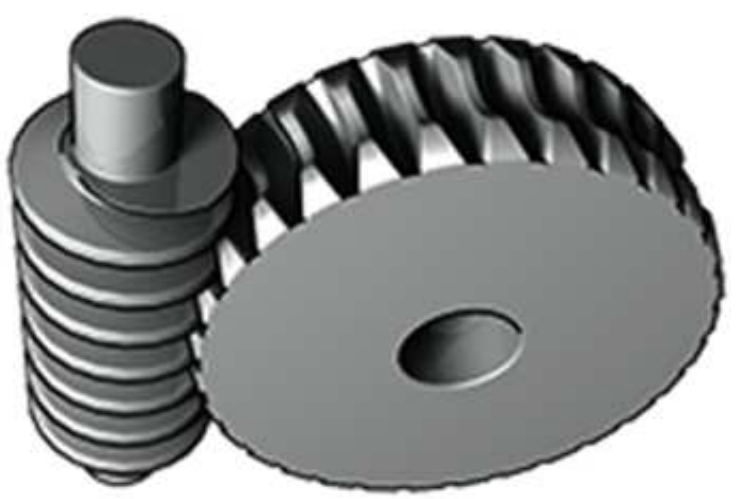

Fig. 33. Worm gears

Wheel or left worm gear transmits a rotational movement between two perpendicular and nonconcurrent axes.

The worm gears are mainly used as reducers, they make it possible to obtain a high reduction ratio (up to $1 / 200$ ) with a small footprint.

This type of gear also has the advantage of offering an irreversible movement, that is to say that the wheel can't drive the worm. It's very practical on our crawlers, it serves as drag brake. On the other hand, this system has a low efficiency, with much loss of power and heating. The lubrication is a particularly important point, the owners of the Losi know it well!

Transmission ratio calculation is done as for straight gears. The number of teeth of the pinion is replaced by the number of threads of the worm. You can see the number of threads of a screw by looking at it from the front (The different types of gears-Webs).

\section{Herringbone Gears}

In 1900, for the Easter holidays andré Citroën leaves to visit family in Poland. While traveling around the world andré meets his brother-in-law, one of whose clients is a small mechanical firm, which has developed a double-sheared gear system with V-shaped teeth. Wooden models, these gears are molded in sand molds and are used inexpensively for flour mills and spinning mills. André sees in this discovery the means to launch his career as an independent industrialist. Indeed, this new technical design makes it possible to transmit significant powers while having a high reduction ratio of the output shaft. Citroën then offered the firm to buy the license of the manufacturing process that was at that time held by the Russians.

Gears with helical teeth contribute to prolonged contact of the teeth during meshing and, at the time, high quality, ensures a quiet operation. The disadvantage is that this induces significant axial forces in the bearings. The double chevron teeth offering a contact in both directions between the rafters compensate for the axial force. 
However, in order to obtain such an interesting operation, it is necessary for the teeth to be perfectly machined. The small Polish firm can't afford such manufacturing precision, or even the large manufacturing companies in Europe. André Citroën then turns to America, where the machine tool manufacturers have a definite lead. Back in France, helped financially by the banker Bronislaus Goldfeder, he transposes the idea with steel rafters. He also developed a milling machine equipped with a profiled cutting tool capable of passing through the steel block from time to time at a turning rate of $2,000 \mathrm{rpm}$, thus achieving the required machining precision.

André Citroen founded in Russia (in Moscow) and organized workshops for the exploitation of his patents for the central empires and the Balkans, in particular for the Skoda Account.

\section{Helical Hinges}

The shape generator of the teeth is a helical line with the same axis as the axis of rotation. This type of toothing has the advantage of being quieter than the straight toothing, creating less vibration. The helical teeth also make it possible to increase the driving of the transmission, by making the number of teeth simultaneously in contact become constant, which makes it possible to transmit greater forces and especially to attenuate the vibrations and the noises.

\section{Gear and Rack Gear}

The rack and pinion system is mainly used to transform a rotary motion into a translational movement or the opposite. It consists of a toothed wheel (Pinion) and a bar also toothed (rack).

The toothed wheel, by turning, drives the teeth of the bar which then moves in translation.

This mechanism is commonly used in automotive steering systems (Fig. 34).

\section{Cutting or Manufacturing of Sprockets and Wheels}

For metal parts, the teeth are mainly made by removing material (machining). It is most often a simulated meshing between a tool (pinion, rack, or milling cutter) and the wheel to be cut. As a result, the tooth module is imposed by the tooling. The engagement movement contributes in all cases to the advance movement in the machining operation.

The cutting action depends on the process.

In the case of plastic parts, the individual parts are generally cut, but for series production they are generally molded.

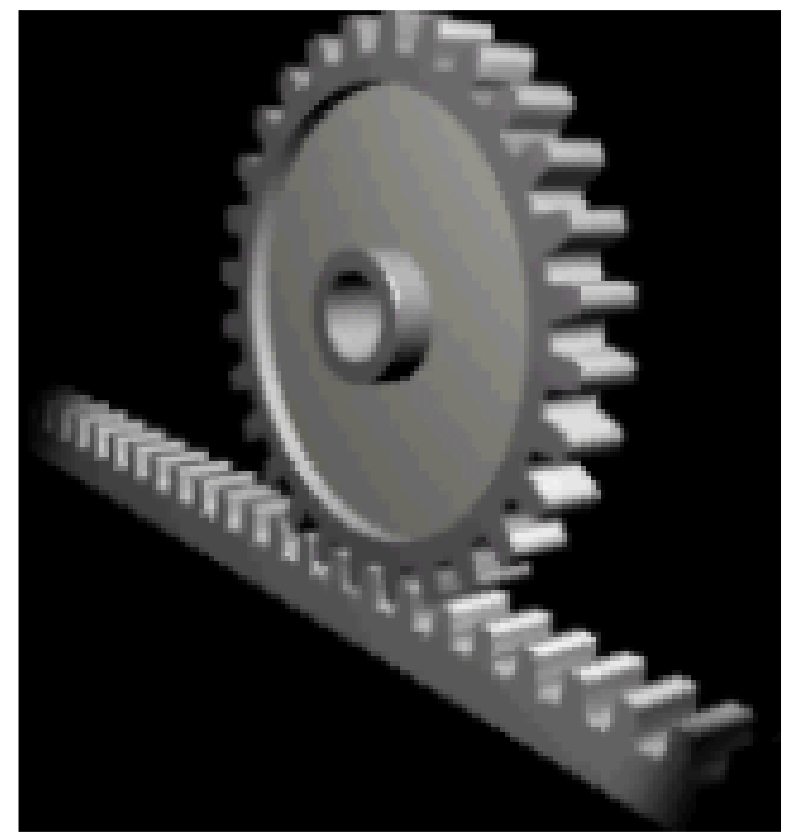

Fig. 34. Gear and rack gear

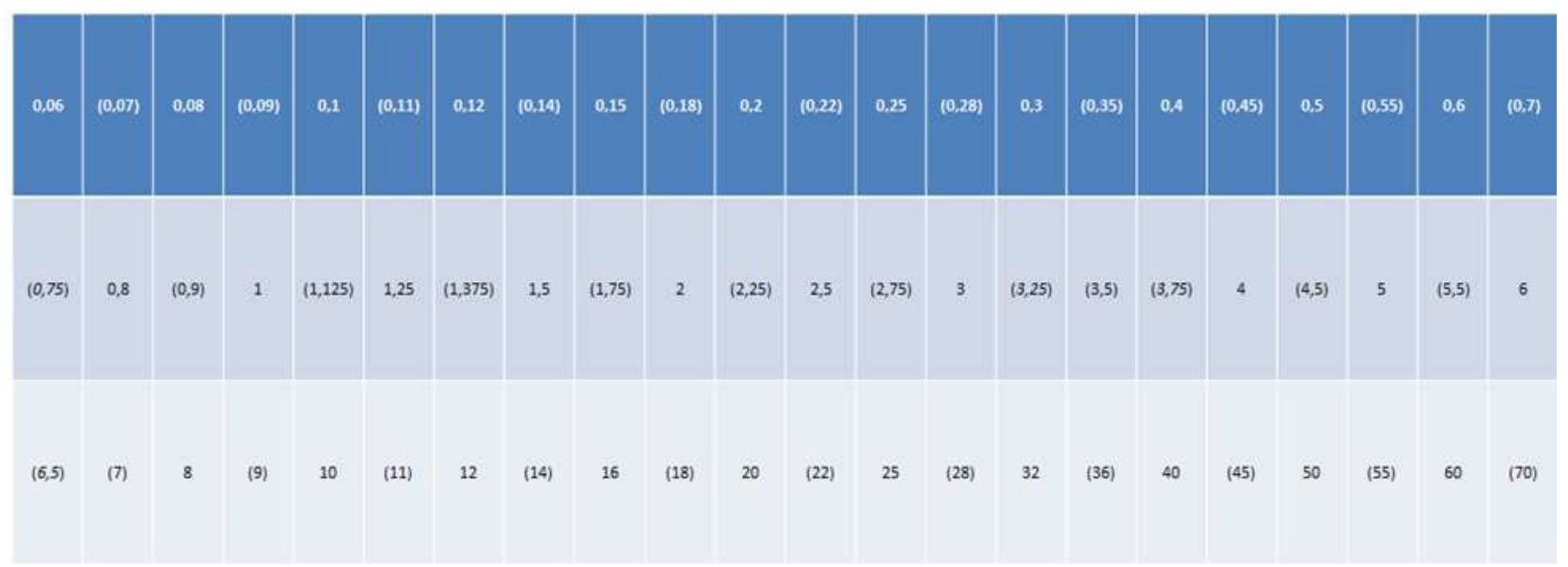

Fig. 35. Module $\mathrm{m}$ is standardized 
The modules are standardized (Fig. 35). There are the main values, the secondary values and the exceptional values (in parentheses and in italics).

\section{Acknowledgement}

The base of this paper, presented by the corresponding author (first time) in 2002, was acknowledged and appreciated by Royal British House, by her scientific adviser, through the British Embassy in Romania in spring-summer of 2002, with wishes of success for the corresponding author and indeed, the work has enjoyed great success.

I wish in this way, to address Her Majesty Queen Elizabeth II, wishes for a long life with health, many achievements and joys. God save the Queen !

\section{Funding Information}

Research contract: Contract number 36-5-4D/1986 from 24IV1985, beneficiary CNST RO (Romanian National Center for Science and Technology) Improving dynamic mechanisms.

All these matters are copyrighted! Copyrights: 394qodGnhhtej from 17-02-2010 13:42:18; 396qkzAdFoDBc from 17-02-2010 17:43:22; 951cnBGhgsHGr from 26-01-2011 16:29:02; 1375tnzjHFAqGF from 02-09-2011 15:19:23.

The cutting action depends on the process.

In the case of plastic parts, the individual parts are generally cut, but for series production they are generally molded.

The modules are standardized (Fig. 35). There are the main values, the secondary values and the exceptional values (in parentheses and in italics).

\section{Author's Contributions}

All the authors contributed equally to prepare, develop and carry out this manuscript.

\section{Ethics}

This article is original and contains unpublished material. Authors declare that are not ethical issues and no conflict of interest that may arise after the publication of this manuscript.

\section{References}

Angelas, J. and C. Lopez-Cajun, 1988. Optimal synthesis of cam mechanisms with oscillating flat-face followers. Mechanism Mach. Theory, 23: 1-6. DOI: 10.1016/0094-114X(88)90002-X

Cao, L., C. Jiang, D. Qin, P. Qiao and G. Liu, 2011. The design and experiments of oval bevel gear. Applied Mechan. Mater. J., 86: 297-300.

DOI: 10.4028/www.scientific.net/AMM.86.297
Gear, from Wikipedia, the free encyclopedia. https://en.wikipedia.org/wiki/Gear

Maros, D., 1958. Cinematica roţilor dinţate. Editura Tehnică, Bucureşti.

Mirsayar, M.M., V.A. Joneidi, R.V.V. Petrescu, F.I.T. Petrescu and F. Berto, 2017. Extended MTSN criterion for fracture analysis of soda lime glass. Eng. Fracture Mechan., 178: 50-59.

DOI: $10.1016 /$ j.engfracmech.2017.04.018

Pelecudi, C.H.R., D. Maros, V. Merticaru, N. Pandrea and I. Simionescu, 1985. Mecanisme. E.D.P., Bucureşti.

Petrescu, R.V. and F.I.T. Petrescu, 2002. Randamentul cuplei superioare de la angrenajele cu roți dințate cu axe fixe. Proceedings of the 7th National Symposium PRASIC, (PRASIC' 02), Braşov, pp: 333-338.

Petrescu, R.V. and F.I.T. Petrescu, 2003. The gear synthesis with the best efficiency. Proceedings of the ESFA, (SFA'03), Bucharest, pp: 63-70.

Petrescu, R.V., F.I.T. Petrescu and N. Popescu, 2007. Determining Gear Efficiency. In: Gear Solutions Magazine, USA, pp: 19-28.

Petrescu, F.I., 2012. Teoria Mecanismelor-Curs si Aplicatii (editia a doua). Create Space Publisher, USA, ISBN-13: 978-1-4792-9362-9, pp: 284.

Rey, G.G., 2013. Influencia de la lubricacion en la eficiencia de engranajes de tornillo sinfin. Ingineria Mecanica J., 16: 13-21.

Stoica, I.A., 1977. Interferenţa roţilor dinţate. Editura DACIA, Cluj-Napoca.

The different types of gears, webs. http://rcshafty.fr/generalites-sur-lesengrenages/\#sommaire

Xiao, L., 2011. Design and analysis for high-speed gear coupling. Applied Mechan. Mater. J., 86: 658-661. DOI: 10.4028/www.scientific.net/AMM.86.658 